\title{
Cuerpos abyectos. Paisajes de contaminación y la corporización de la desigualdad ambiental
}

\section{Abjected bodies. Landscapes of pollution and the embodiment of environmental inequality}

\author{
Débora Swistun ${ }^{1,2}$
}

\begin{abstract}
Resumen
El estudio etnográfico de los efectos sociales de las enfermedades asociadas a tóxicos provenientes de la actividad industrial puede iluminar las vías por las que las desigualdades ambientales están íntimamente corporalizadas, dando una idea de las implicaciones sociales de esos marcadores (in)visibles de desventaja. ¿Cuáles son los efectos sociales de cargar en el cuerpo un paisaje de contaminación? Retomaré el concepto de biología local de Lock, que sintetiza la forma en que la biología difiere por la cultura, la dieta y el medio ambiente y el concepto de biología estigmatizada de Horton y Baker que incorpora a la posición de un sujeto en la estructura social. Cuando miramos un cuerpo podemos descubrir marcas e intuir qué las causaron, qué paisaje habita ese cuerpo y cuál es su lugar (pertenencia social) en la ciudad. A este respecto también importa la definición que hace Meneses de la dimensión de lo visible en un régimen visual: lo visible es la dimensión que envuelve el dominio de poder y de control, el ver o ser visto, el darse o no darse a ver, la visibilidad o invisibilidad. La particular combinación de los conceptos de paisaje, embodiment y biología estigmatizada mediados por el concepto de régimen visual, aquí propuestos, podrían ayudar a entender algunas de las vías simbólicas de la reproducción de la exclusión social en la ciudad y facilitar el análisis de la dimensión corporal en los estudios de flujos de contaminación en la ecología política urbana.
\end{abstract}

Palabras clave: corporización, desigualdad ambiental, flujos de contaminación, paisajes.

\begin{abstract}
The ethnographical study of the social effects of toxic-associated diseases from industrial activity can illuminate the ways in which environmental inequalities are intimately embodied, giving an idea of the social implications of those (in) visible markers of disadvantage. What are the social effects of carrying a pollution landscape in the body? I will return to Lock's concept of local biology, which synthesizes the way biology differs by culture, diet, and the environment, and the stigmatized biology concept of Horton and Baker that incorporates a subject's position in the social structure. When we look at a body we can discover marks and intuit what caused them, what landscape that body inhabits and what is its place (social belonging) in the city. In this respect, Meneses' definition of the dimension of the visible in a visual regime also matters: the visible is the dimension that surrounds the domain of power and control, seeing or being seen, showing oneself or not, the visibility or invisibility. The particular combination of the concepts of landscape, embodiment and stigmatized biology mediated by the concept of visual regime, proposed here, could help to understand some of the symbolic ways of reproducing social exclusion in the city and facilitate the analysis of the bodily dimension in the studies of pollution flows in the urban political ecology field.
\end{abstract}

Key words: embodiment, environmental inequality, flows of pollution, landscapes.

Recibido el 5 de diciembre 2018, aceptado el 13 de diciembre 2018

Cómo citar: Swistun, D. (2018). Cuerpos abyectos. Paisajes de contaminación y la corporización de la desigualdad ambiental. Investigaciones Geográficas, 56, 100-113. https://doi.org/10.5354/07195370.2018 .51995

\section{Introducción}

1 Departamento de Antropología, Universidad Nacional de San Martín. E-mail: dswistun@unsam.edu.ar

2 Departamento de Ciencias Ambientales, Universidad Nacional de Avellaneda. 
Las aproximadamente 1300 familias de la villa Inflamable y el barrio Porst, localizadas en el centro sur de Buenos Aires a solo cinco kilómetros de la Casa Rosada/Puerto Madero, conviven con los gases, combustibles y otros químicos del denominado polo petroquímico de Dock Sud, cuya primera refinería de petróleo de Shell se instaló allí en 1931. Existen allí otra refinería de petróleo (DAPSA), tres plantas de almacenamiento de combustibles y derivados del petróleo (Petrobras, YPF y Petrolera Cono Sur), varias plantas que almacenan productos químicos (TAGSA, Antívari, Dow Química, Solvay Indupa, Materia, Orvol, Cooperativa VDB y Pamsa), una planta que fabrica productos químicos (Meranol), una incineradora de residuos peligrosos (Tri-Eco), celdas antiguas del relleno sanitario CEAMSE, una terminal de containers (Exolgán) y una planta termo eléctrica (Central Dock Sud). Las refinerías de petróleo cotidianamente liberan cantidades importantes de dióxido de azufre, componentes orgánicos volátiles, material particulado, óxidos de nitrógeno, y monóxido de carbono. Las incineradoras emiten dioxinas y metales y los rellenos sanitarios metano entre otros gases. Estos contaminantes forman el nivel base de ozono y neblina. En los años en que no existía legislación ambiental en Argentina, esto es hasta la década de 1980, los vecinos recuerdan que todas las compañías de la zona y de otros municipios del área metropolitana llegaban a los bañados y terrenos vacantes en el barrio para descargar sus desechos industriales tóxicos (Auyero \& Swistun, 2008, p.88).

El haber vivido expuesto a un paisaje como este, una zona de sacrificio, puede dejar efectos duraderos en la salud física de los niños y su desarrollo. La perdurabilidad de los problemas corporales puede actuar, además, como un estigma cuando son adolescentes y jóvenes adultos. En un primer estudio epidemiológico realizado para conocer el estado de salud de los habitantes (JICA, 2003) se comparó una muestra de niños de 7 a 11 años de Villa Inflamable con otra población de control (Villa Corina) de características socio-económicas similares, pero con niveles más bajos de exposición a la actividad industrial. El estudio muestra que en ambas comunidades los niños están expuestos al cromo (conocido cancerígeno listado como un "peligroso contaminante del aire" por la Agencia de Protección Ambiental de los Estados Unidos, acceso online año 2007), benceno (un conocido cancerígeno para el cual no existen umbrales seguros de exposición) y tolueno. Pero es el plomo, "la madre de todos los venenos industriales... la toxina industrial paradigmática causante de enfermedad ambiental" (Markowitz \& Rosner, 2002, p. 137), lo que diferencia a los niños de Inflamable. El $50 \%$ de los niños analizados tienen niveles de plomo en sangre más altos que lo normal (contra un $17.16 \%$ en la población de control). El estudio señala un porcentaje alto (y estadísticamente significativo) de coeficientes intelectuales bajos entre los niños de Villa Inflamable y un porcentaje más alto (también significativo) de problemas respiratorios, de alergias, neurológicos y de conducta (JICA, 2003).

Villar Navascués (2017) realiza una exhaustiva recolección, análisis y sistematización de la producción teórica de la ecología política urbana de los últimos 20 años. En lo que respecta a la categoría de flujos metabólicos son varios los estudios identificados y analizados por el autor que abordan los flujos de contaminación en el espacio urbano. Por ejemplo, desde la perspectiva de la geografía física crítica, identifica el estudio de McClintock (2015) quien analiza la deposición de plomo antropogénico en los suelos urbanos, entendidos como construcciones híbridas socionaturales, lo que permite situar el origen de este flujo de contaminación en el contexto histórico, político y económico en el que fue producido, para denunciar el desigual impacto espacial y étnico de las concentraciones de plomo. Otro estudio se centra en los flujos domésticos de 
contaminación, analizando el legado tóxico del asbesto en las ciudades australianas, así como la influencia de las prácticas cotidianas y de la distinción de clase y de género en el desigual grado de exposición (Houston \& Ruming, 2014). Biehler (2009), por su parte, estudia la exposición a pesticidas tóxicos, asociada a la gestión de plagas, en las viviendas sociales públicas en EE. UU., a lo largo del siglo XX. Una última línea de investigación en torno a esta temática está constituida por los flujos de la contaminación atmosférica (Bruzzelli, 2008; Graham, 2015; Kay, Zhao, \& Sui, 2015; Véron, 2006). Si bien estos estudios emplean una amplia gama de metodologías, y analizan las implicaciones de la gobernanza y las políticas ambientales sobre la desigual repercusión de la contaminación atmosférica en los distintos grupos sociales, entre otros aspectos parecen encontrar un límite y dificultad en el análisis y las implicancias de la dimensión corporal a través de la cual se inscriben los flujos de la contaminación en la ciudad.

La tradición antropológica y especialmente la que investiga la salud y los padecimientos, se ha destacado por abordar, desde el análisis etnográfico, lo corporal en sus distintas manifestaciones. En este artículo se analizan los efectos sociales de estudios epidemiológicos como el JICA anteriormente mencionados y los tratamientos de salud subsiguientes en algunas de las familias con niños con plomo en sangre de la villa Inflamable (polo petroquímico de Dock Sud, Buenos Aires). El estudio de los efectos sociales de las enfermedades de piel asociadas a tóxicos provenientes de la actividad industrial puede iluminar las vías por las que las desigualdades ambientales están íntimamente corporalizadas (embodiment), dando una idea de las implicaciones sociales de esos marcadores (in)visibles de desventaja. Lo visual se transforma en una vía específica a través de la cual se materializa la desventaja socio-espacial como la enfermedad (ambiental), marcando los cuerpos con una ciudadanía de segunda clase señala la antropóloga Nancy Krieger (2001). ¿Cuáles son los efectos sociales de cargar en el cuerpo un paisaje de contaminación? Retomaré el concepto de "biología local" de Lock (1993), que sintetiza la forma en que la biología difiere por la cultura, la dieta y el medio ambiente y el concepto de "biología estigmatizada" de Horton \& Barker (2010) que incorpora a la posición social de un sujeto en la estructura social. Cuando miramos un cuerpo podemos descubrir marcas e intuir qué las causaron, qué paisaje habita ese cuerpo y cuál es su lugar (pertenencia social) en la ciudad. A este respecto también importa la definición que hace Meneses en Marquese ${ }^{1}$ (2010) de la dimensión de lo visible en un régimen visual: lo visible es la dimensión que envuelve el dominio de poder y de control, el ver o ser visto, el darse o no darse a ver, las prescripciones culturales y sociales y los criterios normativos de ostentación o descripción, la visibilidad o invisibilidad. Retomaré el concepto de biología local de Lock (1993), que sintetiza la forma en que la biología difiere por la cultura, la dieta y el medio ambiente y el concepto de biología estigmatizada de Horton y Baker (2010) que incorpora a la posición de un sujeto en la estructura social para responder esta pregunta. La particular combinación de los conceptos de paisaje, embodiment y biología estigmatizada mediados por el concepto de régimen visual, aquí propuestos, podrían ayudar a entender algunas de las vías simbólicas de la reproducción de la exclusión social en la ciudad y facilitar el análisis de la dimensión corporal en los estudios de flujos de contaminación en la ecología política urbana.

1 La categoría de régimen visual, engloba, no sólo el conjunto de imágenes analizadas y sus circuitos de producción, circulación y consumo, sino el lugar del ojo en esos circuitos, esto es, el papel de la visualidad en el conjunto de las relaciones sociales. 


\section{Materiales y métodos}

A través del estudio histórico-etnográfico de una comunidad expuesta a la actividad industrial desde su conformación, se reponen y analizan extractos de entrevistas realizadas entre los años 2004 y 2007, y que fueron empleadas en el análisis de otros aspectos relacionados con el sufrimiento ambiental (Auyero \& Swistun, 2008, 2009). Se analizan por primera vez en este artículo otras entrevistas realizadas a los mismos entrevistados y a otros nuevos entre los años 2012 y 2014, cinco años después de que algunos fueran relocalizados al barrio de vivienda social "San Lorenzo" en la localidad de Wilde (Avellaneda) ubicado a pocos kilómetros del polo petroquímico de Dock Sud. Las entrevistas procuraron rescatar las experiencias de algunos niños con enfermedades ambientales y sus madres cuidadoras respecto de las incertidumbres sobre las consecuencias de la exposición a la contaminación ambiental de su hábitat y respecto de la relación que las marcas corporales tienen con la reproducción de la exclusión social en la ciudad. Los dichos de los entrevistados son repuestos entre comillas en el cuerpo del texto y en citas destacadas respetando las normas del método etnográfico que implica una forma particular de escribir y de aproximarse a la realidad, con el fin de obtener información densa sobre la problemática que se desea investigar. "El etnógrafo o la etnógrafa participa $[\ldots]$ de la vida cotidiana de personas durante un tiempo relativamente extenso, viendo lo que pasa, escuchando lo que se dice, preguntando cosas; o sea, recogiendo todo tipo de datos accesibles para poder arrojar luz sobre los temas que él o ella han elegido estudiar. La etnografía es la forma más básica de investigación social" (Hammersley \& Atkinson, 1994, p.15). Cabe aclarar también que la autora es exhabitante de la denominada villa Inflamable, categorías y conocimientos compartidos con los entrevistados permite un acercamiento diferencial y el extrañamiento metodológico, posicionamiento propio del método etnográfico, permite alcanzar la adecuada distancia epistemológica para el análisis de las entrevistas realizadas.

\section{Las marcas corporales de la desigualdad ambiental}

En 1987 Claudia Romero se mudó a Villa Inflamable. Ella tenía siete años. En ese tiempo, sus padres trabajaban en la por aquel entonces refinería estatal YPF (Yacimientos Petrolíferos Fiscales). Después de algunos años de vivir en Florencio Varela, provincia de Buenos Aires, los padres de Claudia encontraron un lugar para vivir frente a YPF, Shell y otras compañías del Polo Petroquímico y Puerto Dock Sud. Su familia ha estado viviendo en el barrio desde hace veinte años. Claudia hoy tiene 33 años, está casada con Carlos Romero y tiene cuatro hijos. Tanto Carlos como Claudia trabajaban como personal de limpieza en dos de las compañías del polo, pero perdieron sus trabajos hace algunos años. Carlos salía de su casa cada tarde para "cirujear" por el centro de Avellaneda, "de punta a punta por la Avenida Mitre". "En una buena semana, hago 25 pesos", nos contaba. Claudia no ha encontrado un trabajo y es beneficiaria de un Plan Jefas y Jefes de Hogar: "Juntos hacemos cerca de 250 pesos al mes y con eso tiramos. Cocinamos una vez al día, a la noche." Para el almuerzo, los chicos comen pan con leche, la única comida completa es la cena. Los fines de semana asisten a uno de los comedores comunitarios del barrio. Estas necesidades económicas de los Romero compiten con la atención a los constantes problemas de salud de dos de sus hijos. "Dos de ellos", Claudia remarca, "tienen problemas. Los otros dos andan bien.” El más pequeño, Julián, de 5 años, tenía convulsiones desde que es bebé:

"Él nació con esta marca en su cabeza. Los doctores me dijeron que no era nada. Que era sólo una marca de nacimiento. Después empezó a tener convulsiones y empecé a ir de un hospital a otro. En el Hospital de Niños le sacaron una tomografía y salió que su cerebro está 
afectado por esa marca, que no está sólo afuera, sino adentro también. Y ahora tiene ese angioma rojo que está aflorando. Mirá, Julián, mostráselo.” (Claudia, 27 años, 2004)

Cuando Julián nos mostró su prominencia roja, le preguntamos a Claudia acerca de lo que diagnosticaron los médicos: "Ellos no me explicaron nada", responde, "ellos no saben por qué tiene esa marca. Yo me hice el análisis, su papá también, y no tenemos nada. No nos analizaron por plomo porque ellos no lo cubren. Y nosotros no lo podemos pagar". A Julián se le prescribió un anticonvulsivo. Claudia recibe un frasco de Epamil gratis por mes en el hospital público local, "pero Julián usa dos o tres frascos. Y eso sale entre 18 y 20 pesos cada uno, y algunas veces no podemos comprarlo. Yo empecé el papeleo para ver si podemos tenerlo gratis. Todo el mundo me prometió, pero no pasó nada. Papeles, papeles, papeles, sólo palabras." Julián necesita un control diario por sus convulsiones, pero ya ha pasado bastante tiempo desde su último chequeo:

"Ahora tenemos un turno para agosto. Puede morir antes de eso, pero yo debo esperar. Algunas veces él convulsiona dos veces al día, y no tengo medicación. Ahora no tengo suficiente dinero [para pagar el colectivo] para ir al hospital. Los chicos acá siempre están enfermos, con bronquitis, con un resfrío." (Claudia, 27 años, 2004)

Sofía, otra de sus hijas, nació con su pierna izquierda significativamente más corta que la derecha, siempre tiene dolores de cabeza y de estómago: "Cuando me hicieron el primer ultrasonido, me dijeron que ella iba a nacer con problemas. Cuando les dije a los doctores que vivía acá, me dijeron que tenía que hacerme el análisis de plomo. Yo no pude pagar los análisis. Los doctores me dijeron que el plomo pudo haber causado el problema de la pierna." Más tarde, Sofía comenzó a mostrar serias dificultades para aprender: "Ella tiene problemas para recordar los números, le cuesta mucho realmente." Claudia misma no está en buena forma. Parece que tuviera mucho más que 27 años. Perdió la mitad de sus dientes; y siempre parece que está cansada: "Yo tengo todos los síntomas", aludiendo al posible envenenamiento con plomo, "tengo calambres, sangre que me sale de la nariz, dolores de cabeza. Desde hace tres o cuatro años que me duele todo". Cuando el dolor es insoportable, ella se atiende en la unidad sanitaria del barrio: "Y los médicos me dan alguna aspirina. Yo me siento mejor, pero después el dolor vuelve. Y de noche es peor." Cuando le preguntamos sobre su nivel de plomo en sangre, nos dijo que los estudios son muy caros para ella: "cuestan entre 100 y 200 pesos." Claudia sabe que no es la única que tiene un cuerpo que duele e hijos enfermos. El problema, dice, "está por todos lados":

"Yo realmente no entiendo de números, pero mi sobrino tiene $50 \%$ de plomo [refiriéndose a 50ug/dl (microgramos por decilitro) por encima de los $5 \mathrm{ug} /$ dl que es lo considerado normal]. Mi hermana puede pagar los estudios porque su marido trabaja en Shell. Ella supo que tenía niveles altos de plomo cuando estaba embarazada [...] Pero ella no está haciendo nada. No se hace ningún tratamiento porque eso le causaría problemas a su marido que trabaja en Shell. Si ellos se llegaran a enterar de que ella se hizo el análisis, él perdería su trabajo. Algunas veces quiero matarla. Es como si ellos tuvieran miedo. Pero creo que los chicos son más importantes. ¿Y la vida de sus hijos? Su hijo no aumenta de peso. Es muy flaco y parece amarillo. Él tiene miles de problemas, pero ella no hace nada. Hay muchos chicos con problemas acá." (Claudia, 27 años, 2004)

Cuando le preguntamos acerca de las reacciones que los doctores tienen ante estos problemas, ella dice: "Nada, no dicen 
nada. Una de las doctoras se fue porque empezó a sentirse mal y encontró que tenía plomo en la sangre. Ella estuvo sólo por un año, imagínate como debemos estar nosotros"

En junio de 2008, la Corte Suprema de Justicia de la Nación ordenó que los distintos niveles de gobierno (nacional, provincial y municipales) presentasen un plan de limpieza del Riachuelo (Villa Inflamable está ubicada en la boca del Riachuelo). La Corte Suprema ordenó que cuarenta y cuatro empresas (entre ellas Shell, Petrobras y Central Dock Sud) informaran sobre sus programas de tratamiento de residuos. La Corte Suprema respondía así a una demanda presentada por varios abogados en representación de ciento cuarenta vecinos de Dock Sud (entre ellos, muchos de Inflamable). Los abogados también solicitaban la creación de un fondo de compensación para las "víctimas de la contaminación" quienes, de acuerdo al texto de la demanda, sufrían envenenamiento con plomo, malformaciones congénitas y abortos espontáneos. Si bien la Corte Suprema ordenó a las compañías y a los gobiernos que presentaran planes y reportes, no produjo sentencia en relación a la creación del fondo de compensación, lo cual, según estableció la Corte, es materia de jueces de primera instancia.

María del Carmen Brite es una de las litigantes en la causa que llegó a los estrados de la Corte Suprema. Desde que en Inflamable la contaminación surgió como un tema a ser considerado, ella ha sido una voz prominente contra sus efectos perjudiciales en los niños y niñas del barrio (los suyos incluidos). El primero de enero del año 2004, una nota titulada "A treinta cuadras del obelisco, una zona con raros olores químicos" fue la primera en describir el padecimiento de María del Carmen:

"La casa de María del Carmen está ubicada en medio del polo petroquímico. Nos muestra las radiografías de los pulmones dañados de su hija, Camila, quien tiene 4 años. Camila tiene serios problemas respiratorios. Su historia clínica indica sufrimiento fetal debido a la inhalación de ácido. Y su hermano, Emir, tiene sus piernas marcadas por manchas enormes y oscuras." (Auyero \& Swistun, 2008).

Cuatro años más tarde, este mismo periódico, retrata a la familia Brite aun viviendo en Inflamable: "Esto es sólo una alergia", dice María del Carmen refiriéndose a Emir (ahora de 10 años), "pero no sabemos lo que tiene adentro". En una conversación anterior a la nota periodística del 2004, la vecina de Inflamable nos había dicho que "Emir está lleno de granos, no puede usar pantalones cortos. Parece un sarnoso. No lo puedo llevar a la pileta [del club local de Avellaneda] porque no lo dejan entrar". Refiriéndose a al reciente fallo de la Suprema Corte, María del Carmen le dice a los periodistas de Clarín: "No queremos plata. Sólo queremos que nos paguen los tratamientos. Nos estamos muriendo de a poco" (Auyero \& Swistun, 2008, p. 188).

Cuando hicimos el trabajo de campo entre 2004 y 2007 María Soto vivía en Villa Inflamable desde hacía veinte años. Habitaba una precaria casa de madera frente a la industria Petrobrás cuyo fondo era una pequeña barranca repleta de basura que se inclina hacia un mugriento pantano. No tenía trabajo, se había desempeñado como personal de limpieza en varias plantas del polo; era una de las cientos de miles de beneficiarias del Plan Jefas y Jefes de Hogar. María y su marido, Pedro (quien trabajaba como remisero y era también beneficiario del mismo plan), apenas lograban subsistir con sus tres hijos. Todos los lunes, María asistía a un taller organizado para madres con hijos e hijas con problemas de desnutrición, en la escuela local y con fondos provistos por Shell. Allí, todos los meses, María recibía comida gratis. Junto a los comedores 
comunitarios financiados por el Estado en donde sus hijos comían a diario, lograba a duras penas "llegar a fin de mes". María Rosa, la hija de María, tiene 11 años. De acuerdo a un análisis de sangre que se había hecho en el 2003, tenía altos niveles de plomo en sangre $(18,5 \mathrm{ug} / \mathrm{dl}$, microgramos por decilitro, bastante por encima de lo que se consideran niveles normales hoy [5 ug/ dl]). Eso explicaría las difíciles noches de María Rosa ("duerme sobresaltada", nos contaba María), sus aleatorios picos de fiebre y sus ocasionales convulsiones. "Yo le dije al doctor lo de la fiebre y la tos", dice María, "y el doctor me dijo que es porque el plomo te consume lentamente".

María sabe que hace algunos años un vecino murió de saturnismo, dos mujeres se quedaron ciegas, otras tres contrajeron leucemia, y cuatro fueron operadas de distintos cánceres y teme por María Rosa: "Tengo miedo por mi hija". El tratamiento que, financiado por el Estado, María Rosa llevaba a cabo fue suspendido en 2006 y María no tiene certeza alguna sobre cuándo será reiniciado. Si Rosa quiere curarse, María cree, tiene que "comenzar un tratamiento, tomar algún remedio, así de la nada no se va a curar". María cree que su hija "fue contaminada por las fábricas" y apunta a la "planta de coque" como la principal responsable. Las plantas dentro del polo, dice, emiten partículas que dejan "toda sucia" la ropa que ella cuelga a secar: "Algunos días el olor que viene de ahí te mata, eso nos hace mal".

La investigación sobre los orígenes y efectos del plomo es vasta (Berney, 2000; Warren, 2000; Markowitz \& Rosner, 2002; Widener, 2002). El plomo en el medio ambiente es producto de su uso en la industria y se acumula en el cuerpo humano (en la sangre, en los tejidos y en los huesos) en proporción a la cantidad que se encuentra en el medio ambiente. Es absorbido por el cuerpo desde el ambiente y esta absorción (medida en la materia fecal, en la orina, en la sangre y en los tejidos) es un indicador de exposición y envenenamiento (Berney, 2000, p.238). De acuerdo a la Agencia de Protección Ambiental de los Estados Unidos [U.S.EPA, 2008] el plomo "puede causar una gama de efectos en la salud, desde problemas de conducta hasta problemas de aprendizaje, convulsiones y muerte". Es un veneno que afecta el cerebro, los riñones y el sistema nervioso de formas muy sutiles y con dosis bajas (sobre el cambio histórico en los niveles que son considerados "normales", ver Berney, 2002; Widener, 2000). Una alta exposición al plomo puede causar "encefalopatía y muerte, dosis más bajas causan retardos severos, dosis menores producen problemas en la escuela, pequeños pero significativos cambios en el coeficiente intelectual, y otros efectos en el sistema nervioso central" (Berney, 2000, p. 205).

Provenientes de la actividad industrial el cromo y el tolueno también son otras de las sustancias que fueron halladas en el ambiente de Inflamable. El cromo es un conocido metal cancerígeno listado como un "peligroso contaminante del aire" por la Agencia de Protección Ambiental de Estados Unidos U.S. EPA (2005). De acuerdo a la EPA de los Estados Unidos: "El sistema nervioso central (SNC) es el blanco principal para la acción tóxica del tolueno tanto en humanos como en animales, tanto en exposiciones cortas como crónicas. Disfuncionalidad y narcosis en el SNC han sido observadas frecuentemente en humanos expuestos a períodos cortos de inhalación de tolueno; los síntomas incluyen fatiga, somnolencia, dolores de cabeza y náuseas. [...] La exposición a la inhalación crónica en los humanos también causa irritación del tracto respiratorio superior y ojos, dolor de garganta, mareo y dolor de cabeza. Estudios en humanos han reportado efectos en el desarrollo, tales como disfunciones en el SNC, déficit atencional y anomalías craneofaciales y en las extremidades, en los hijos de mujeres que durante su embarazo 
estuvieron expuestas a la inhalación de tolueno o mezcla de solventes. [...] EPA ha clasificado al tolueno en el Grupo D, no cancerígeno"

Como remarcan muchos manuales sobre toxicología ambiental y del desarrollo (Yassi, Kjellstrom, De Kok, \& Guidotti, 2002) los niños son los más vulnerables, sus cuerpos todavía se están desarrollando $y$ el efecto de una agresión ambiental puede interferir en el crecimiento. La investigación de cómo las toxinas pueden afectar al feto y al desarrollo del niño es llamada toxicología del desarrollo. El valor del metabolismo de los niños es mucho más alto que el de un adulto, en parte porque ellos todavía están desarrollándose y en parte porque son más pequeños. Esto significa que su capacidad respiratoria, por ejemplo, es proporcionalmente mayor y ellos aspiran mucha más contaminación del aire en relación a su peso corporal que un adulto en circunstancias similares. Los niños también tienen una oportunidad mayor que los adultos de experimentar efectos crónicos de exposición a peligros ambientales, porque cuando ellos se exponen a un carcinógeno las oportunidades son mucho más altas, ya que vivirán más allá del período de latencia (los años que toma un cáncer para desarrollarse después de la exposición) (Yassi et. al, 2002, p.40).

\section{Un modelo antropólogico de análisis de la corporización de la desigualdad ambiental}

Horton \& Barker (2010, p. 201) señalan que existe una rica tradición en la investigación antropológica que examina cómo la cultura da forma a la experiencia y la expresión de los padecimientos corporales (Csordas, 1994; Good, 1994; Kleinman, 1988; Lock, 1993); y aunque los antropólogos han empleado la variación cultural, para la crítica de la noción del cuerpo como una invariante biológica universal, su excesivo énfasis en la cultura ha oscurecido la relevancia de la posición de esos sujetos en la estructura social. Como muestra el relato de Claudia, la desventaja producida por la estratificación social expresada en el espacio habitado (contaminado) deja su huella en su fisiología y fisonomía y en la de sus hijos en innumerables maneras.

En esta línea de trabajo los mismos autores remarcan que los investigadores en salud pública han girado su interés hacia el paradigma del embodiment, instando a la consideración de los factores ambientales que los antropólogos han descuidado durante mucho tiempo. La antropóloga Nancy Krieger, (2001, p. 672) por ejemplo, utiliza el concepto de embodiment para examinar cómo los individuos "literalmente incorporamos biológicamente el mundo material y social en el que vivimos" (2001, p.672). Para Krieger, el concepto de embodiment nivela la antinomia que se percibe entre lo "social" y lo "biológico". Su modelo critica los enfoques biomédicos y psicosociales centrados exclusivamente en las respuestas biológicas endógenas que ignoran los determinantes sociales de la salud. Su perspectiva proporciona una potente y fina herramienta conceptual para examinar los determinantes biológicos y sociales conjuntos de la salud.

Instando a atender la interacción entre lo biológico y socio-político en múltiples niveles, propone que los estudiosos analicen las vías específicas a través de las cuales se materializa la desventaja social como la enfermedad y la discapacidad. Ella muestra, por ejemplo, cómo el exceso de riesgo de hipertensión entre los afroamericanos es la encarnación física/corporización (embodiment) de una míriada de factores materiales y sociales, incluyendo la segregación residencial y ocupacional, la exposición a sustancias tóxicas, la discriminación interpersonal, el marketing dirigido de los productos básicos y la atención médica inadecuada. $\mathrm{Su}$ modelo desenmascara patrones poblacionales de la salud y la enfermedad como "expresiones biológicas de relaciones 
sociales" (Krieger, 2001, p. 672). Aún más provocativamente, su enfoque permite la interacción acumulativa entre el desarrollo biológico y la estructura social, teniendo en cuenta los efectos sobre la salud a largo plazo de las desigualdades corporalizadas tempranamente en la vida (Krieger, 2001, p. 673).

Este modelo es sugerente para una aproximación antropológica a la forma en que los factores sociales, culturales, y políticos median las disparidades en salud de niños y mujeres en situación de desventaja ambiental (contaminación del agua y suelo por falta de cloacas, red de agua segura y recolección de basura; contaminación del aire por emisiones tóxicas industriales) y por lo tanto para los estudios de flujos de contaminación en la ecología política urbana. Las denominadas enfermedades ambientales ofrecen una ocasión propicia para examinar la interacción a largo plazo entre la biología y la estructura social. Los niños con disparidades de desarrollo psicomotriz y neurológico, tóxicos en sangre y enfermedades de la piel sufrirán efectos a largo plazo a medida que interactúan con circunstancias sociales futuras. De hecho, las enfermedades ambientales tienen importantes efectos duraderos tanto en la salud sistémica como en el desarrollo social de los niños a largo plazo.

Susana llegó a Inflamable en 1995. Construyó su casa de chapa sobre un terreno cuyo fondo da a una laguna contaminada. Con fondos provistos por el estado municipal y por algunas empresas del polo, organizaba un comedor comunitario en su casa. Tiene una hija y tres hijos, uno de ellos, Ezequiel (12 años), fue examinado durante el estudio de JICA y tiene niveles muy altos de plomo en sangre. Lo que sigue son extractos de una conversación de dos horas que mantuvimos con ella en marzo del año 2006. El diálogo introduce varios de los temas que nos interesan: los efectos corporales de la contaminación, el estigma, las dudas, y la política pública en salud dirigida hacia ellos.

"Ezequiel tiene vergüenza de salir en pantalón corto, por los granos. Tiene como marcas por todos lados. Gracias a Dios, nunca en la cara. Le compré pantalones largos para que se tape los granos. A la noche no duerme. Le pica todo, la espalda, los brazos, las piernas. A Manuel [su segundo hijo] ahora le están saliendo manchas. Ahora estoy esperando a los abogados. Van a venir a hacer los estudios, pero no sé qué pasa, porque todavía no vinieron. Yo los llamé y no vinieron." (Susana, marzo 2006)

"Cuando empezaron a llamar a los chicos para el estudio del plomo [en el año 2001], empecé a pensar en lo de los granos. [...] Cuando me dijeron que tenía plomo, empecé a pensar en lo de la contaminación. Los doctores [en el centro de salud local] me dijeron: "No, señora, no se asuste. No es nada". Y ahora, no sé. Es como si nada hubiera pasado con lo del plomo. De la municipalidad no vinieron más. Y no hubo más exámenes." (Susana, marzo 2006)

La mayoría de los entrevistados señala que si no pueden acceder a tratamientos para "descontaminarse" y si siguen "viviendo allí los chicos no van a curarse". Muchos de ellos también han experimentado en sus propios cuerpos que cuando salen del barrio y se quedan a dormir en casas de familiares o amigos que no viven "al lado de industrias" pueden "descansar mejor y dormir sin sobresaltos, ni olores raros". Quelación es el nombre de la terapia indicada para reducir niveles altos de plomo en sangre y a la que los niños participantes del estudio JICA fueron sometidos después de que los resultados de los análisis revelaran que sobrepasaban los niveles tolerables de plomo. Las indicaciones para esa terapia varían según 
la edad del paciente; el nivel sanguíneo de plomo y la sintomatología clínica. La vía de administración de los agentes quelantes ${ }^{2}$ (como el edetato de calcio disódico) es intramuscular y endovenosa y requiere internación. También existen tratamientos ambulatorios con medicación oral pero es un tipo de tratamiento que no está disponible en Argentina en el sistema de salud público. Se considera que la quelación no es una panacea para la intoxicación plúmbica por sus efectos adversos (al arrastrar el plomo de diversos tejidos el quelante también arrastra nutrientes) y porque tampoco hay evidencia que los agentes quelantes tengan acceso a sitios críticos de la acción tóxica del plomo, tales como el sistema nervioso central. Por lo cual, para que la terapia sea eficaz lo más importante es que los pacientes sean alejados de la fuente de exposición al plomo. Lamentablemente los niños luego de la quelación volvieron a vivir en Inflamable hasta que se implementó la relocalización de ellos y sus familias en el Barrio San Lorenzo como veremos más adelante en este apartado.

Durante el año 2013 volví a encontrarme con Susana y su hijo, cinco años después de que fueron relocalizados a un barrio de viviendas en Wilde. Si bien ya no habitaban junto al polo, el nuevo hábitat tiene algunas falencias de saneamiento integral urbano. Cuando le pregunté a Susana sobre la salud de Ezequiel, dijo que apenas se mudaron les habían realizado estudios de plomo a todos los chicos de las veinticinco familias provenientes de Inflamable, si bien "el municipio les dijo que tenía cero [plomo], que no tenían nada", ella sospechaba que no era así porque "¿tan rápido no te puede bajar y además justo a todos nos daba cero?" se preguntaba en voz alta. Debido a su falta de recursos económicos no habían vuelto a hacerse análisis de plomo por lo cual no sabe "a ciencia cierta si su salud ha mejorado o no", pero ella piensa que no, debido a que Ezequiel continúa con dolores de cabeza y granos esporádicos en las piernas que ella asocia al plomo porque los doctores no le encuentran nada. Él hoy ya es un joven de 18 años y siente la misma vergüenza que cuando era un niño por sus marcas que aún esconde con pantalones largos cuando va a jugar al fútbol. También está preocupado que en su trabajo no se enteren que tiene plomo, porque él cree que si lo saben lo despedirían. Otras madres me han expresado el mismo temor, aunque no podría comprobar si es cierto que alguien fue despedido de su trabajo por tener plomo en sangre más alto de lo considerado "normal". Como se desprende de la entrevista la presencia de plomo en sangre puede afectar negativamente la autoestima de un niño y su capacidad de relacionamiento con sus pares tanto como su fisonomía. Entonces el estudio de esas enfermedades de piel asociadas a tóxicos en el ambiente y la sangre puede iluminar las vías por las que las desigualdades ambientales están íntimamente corporalizadas, dando una idea de las implicaciones sociales de esos marcadores visibles de desventaja.

Consciente de sus marcas en las piernas y brazos, Ezequiel trata de evitar jugar al futbol con pantalones cortos y más aún importante para su crecimiento económico e independencia futura, ruega para que en su trabajo no sepan que tiene plomo en sangre. Al igual que en el caso de los niños estudiados por Horton \& Barker (2010) con enfermedades periodontales severas, la desfiguración percibida por Ezequiel y otros jóvenes con sufrimiento ambiental

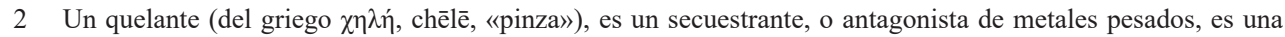
sustancia que forma complejos con iones de metales pesados. A estos complejos se los conoce como quelatos, palabra que proviene de la palabra griega chele que significa "garra". Los metales pesados no pueden ser metabolizados por el cuerpo humano y persisten en el organismo, donde ejercen sus efectos tóxicos cuando se combinan con uno o más grupos reactivos (ligandos) esenciales para las funciones fisiológicas normales. Los quelantes se diseñan para competir con los metales por los grupos reactivos fisiológicos, evitando o revirtiendo así sus efectos tóxicos e incrementando su excreción 
los ha llevado a desarrollar una tipo de identidad como la que Goffman (1970) denomina el "deshonroso". Parafraseando a Goffman, Ezequiel al usar panatalones largos para jugar al futbol, intenta contener este daño a su sentido del yo a través de la evitación de situaciones en las cuales la desfiguración se hace visible. No son marcas de las que sientan orgullo, como las que señala Miguez (2002) en el análisis de la relación entre cuerpo, identidad, y pertenencia social de jóvenes de sectores populares en programas de recuperación de adicciones y delincuencia cuyas prácticas corporales performan desafiando los umbrales de vergüenza modernos de las clases profesionales. A pesar de esta diferencia, pero al igual que en los cuerpos que analiza Miguez, los jóvenes de Inflamable también desarrollan una serie de técnicas corporales, como el jugar al futbol con pantalones largos, que les permiten subsistir en situaciones adversas.

A estas alturas queda claro que los cuerpos de los niños y jóvenes que habitan paisajes de desventaja ambiental son los que más sufren los efectos de las llamadas "externalidades negativas" del desarrollo urbano-industrial moderno ${ }^{3}$. Respecto del caso del hijo de Maria del Carmen al cual no dejan entrar a la pileta por sus granos y marcas en las piernas, hay otra reflexión que puede extraerse de la estética visual que emanan estas biologías estigmatizadas y es el concepto de lo abyecto en Julia Kristeva (1982) quién inspirada en el psicoanálisis señala que tales cuerpos causan abyección no sólo por la falta de limpieza o por la posibilidad de transmisión de fluidos y enfermedades sino también y principalmente porque perturban ficciones de identidad, sistema y orden. Así García y su esposa, vecinos de toda la vida del barrio Porst adyacente a la villa Inflamable y que trabajaron en las empresas del polo, afirman -contrariamente a lo que demuestran diversos estudios- que "esos chicos están así porque sus madres no los cuidan y los dejan en la calle además de que la contaminación que causa esas enfermedades no está en el barrio Porst, la traen ellos".

Si bien diversas apropiaciones estatales de la vulnerabilidad de estas "biologías estigmatizadas" ha generado diversas políticas de salud a partir de la sentencia de la corte suprema de justicia de Argentina ${ }^{4}$, la presencia de estos cuerpos con marcas que no se quieren ver perturba a los vecinos más antiguos de barrio Porst que sostienen el mito de que "la parte que ellos habitan no está contaminada" y también a usuarios de lugares públicos como la pileta del club de deportes local. La visualidad que emana de los cuerpos de los niños y jóvenes contaminados de Inflamable designaría en términos de Butler (2002, p. 19-20) evocando a Kristeva, "aquellas zonas "invivibles", "inhabitables" de la vida social que, sin embargo, están densamente pobladas por quienes no gozan de la jerarquía de los sujetos, pero cuya condición de vivir bajo el signo de lo "invivible" es necesaria para circunscribir la esfera de los sujetos. Esta zona de inhabitabilidad constituirá el límite que defina el terreno del sujeto; constituirá ese sitio de identificaciones temidas contra las cuales -y en virtud de las cuales- el terreno del sujeto circunscribirá su propia pretensión a la autonomía y a la vida. En este sentido, pues, el sujeto se constituye a través de la fuerza de la exclusión y la abyección, una fuerza que produce

3 En el ámbito rural abundan estudios que señalan los efectos de la contaminación por plaguicidas con glifosatos utilizados en el cultivo de la soja. El trabajo de Silva (2009) en uno de los primeros en ofrecer un panorama de las enfermedades asociadas a dichas actividades agrícolas, y los efectos de la exposición involuntaria en los poblados cercanos. Otros investigadores también analizan los daños al medioambiente y los pueblos que conviven con las actividades extractivas de la minería a cielo abierto y de los impactos ambientales y a la salud de las actividades extractivas del petróleo.

4 Veáse Swistun, 2013, para un análisis de las políticas de relocalización y programas de salud dirigidos hacia ellos. 
un exterior constitutivo del sujeto, un exterior abyecto que, después de todo, es "interior" al sujeto como su propio repudio fundacional."

Al mismo tiempo que políticas más estrictas del control de la contaminación sean implementadas, los tratamientos "descontaminantes" serán la diferencia en la vida de Ezequiel y otros chicos que nacieron en Inflamable y que fueron relocalizados a un hábitat menos expuesto a la actividad industrial, aun cuando las marcas corporales visibles de la exposición crónica a un ambiente contaminado puedan ya no desaparecer y detener la reproducción de una "biología estigmatizada".

El paisaje de contaminación que estos cuerpos llevan a cuestas, como "biologías estigmatizadas", representa la "zona invivible, inhabitable" de nuestras ciudades modernas. Las imágenes de disgusto que esos cuerpos provocan en la dimensión visual de la vida social, se constituyen en elementos de un régimen visual que coadyuva a la reproducción de la exclusión de estos jóvenes de los espacios donde los cuerpos no abyectos disfrutan de los "derechos de ciudadanía".

\section{Conclusiones}

A partir de los relatos de los padecimientos de madres e hijos que sufren las enfermedades ambientales causadas por la contaminación del paisaje habitado, e inspirados en los conceptos de estigma y biología local y sus posteriores adaptaciones hasta aquí demostré una de las vías de creación y reproducción de la desigualdad y la exclusión social a través del rol de la dimensión visual en la dinámica de los flujos de contaminación ambiental urbana. A través de los relatos vimos cómo dichas desventajas corporales (in)visibles generan perdurables efectos en la salud y en el desarrollo personal de niños afectados por la contaminación ambiental, todo lo que a su vez afecta su sentido del yo cuando llegan a la adolescencia y a la adultez joven. No sólo a través de marcadores visibles en el cuerpo se reproduce un sistema de desigualdad social sino que a través de los relatos nos dimos cuenta también que los marcadores invisibles, aquellos que la toxicología denomina "biomarcadores de exposición a la contaminación" (plomo en sangre, cromo, arsénico, mercurio, ácido transmucónico, bioindicador de exposición a benceno y orto cresol, bioindicador de exposición a tolueno, en orina), que se traducen en vergüenza, también afectan el deseo de movilidad social de estos jóvenes (entendida por ellos como un trabajo seguro o el acceso a espacios de recreación pública) si ese "secreto biológico" se hiciera público. Así los flujos (in)visibles de la contaminación en los paisajes urbanos, atraviesan los cuerpos y co-crean biologías e identidades específicas, que los estudios de la ecología política urbana debieran considerar para poder explicar con mayor profundidad la producción y los efectos de la desigualdad ambiental en nuestras ciudades.

\section{Bibliografía}

Auyero, J. \& Swistun, D. (2008). Inflamable. Estudio del sufrimiento ambiental. Buenos Aires: Paidós. ISBN 9501245454, 9789501245455

Auyero, J. \& Swistun, D. (2009). The social production of toxic uncertainty. American Sociological Review, 72(3), 357-379. https:// doi.org/10.1177/000312240807300301

Auyero, J. \& Swistun, D. (2009). Flammable. Environmental suffering in an Argentine shantytown. New York: Oxford University Press. ISBN-10: 019537293X. ISBN-13: 978-0195372939

Berney, B. (2000). Round and round it goes. The epidemiology of childhood lead poisoning, 1950-1990. En S. Kroll-Smith, P. 
Brown, \& V. Gunter, (Eds.), Illness and the environment. A reader in contested medicine. (pp. 235-57). Nueva York: NYU Press.

Biehler, D.D. (2009). Permeable homes: A historical political ecology of insects and pesticides in US public housing. Geoforum, 40(6), 1.014-1.023. https://doi.org/10.1016/j. geoforum.2009.08.004

Bruzzelli, M. (2008). A political ecology of scale in urban air pollution monitoring. Transactions of the institute of British geographers, 33(4), 502-517. http://dx.doi. org/10.1111/j.1475-5661.2008.00316.x

Butler, J. (2002). Cuerpos que importan: sobre los límites materiales y discursivos del sexo. Buenos Aires: Paidós. ISBN: 97895012381

Csordas, T. (1994). Embodiment and experience. Cambridge: Cambridge University press. ISBN: 9780521458900

Goffman, E. (1970). Estigma. La identidad deteriorada. Buenos Aires: Amorrortu editores. ISBN 10: 950-518-016-0

Good, B. (1994). Medicine, rationality, and experience: An anthropological perspective. Cambridge, Cambridge University Press. ISBN 10: 9780521425766 . ISBN 13: $978-$ 0521425766

Graham, S. (2015). Life support: The political ecology of urban air. City, 19(2-3), 192-215. http://dx.doi.org/10.1080/13604813.2015.10 14710

Hammersley, M. \& Atkinson, P. (1994) Etnografia. Métodos de Investigación. Barcelona: Paidós Ibérica. ISBN: 9788449309809

Horton, S. \& Barker, J. (2010). Stigmatized biologies: Examining the cumulative effects of oral health disparities for Mexican American farmworker children. Medical anthropology quarterly, 24(2), 199-219. https://doi. org/10.1111/j.1548-1387.2010.01097.x

Houston, D. \& Ruming, K. (2014). Suburban toxicity: A political ecology of asbestos in Australian cities. Geographical research, 52(4), 400-410. http://dx.doi. org/10.1111/1745-5871.12075

Japan International Cooperación Agency [JICA] (2003) Ambiente y salud. Plan Acción estratégico 2003. Convenio Secretaría de Ambiente y Desarrollo Sustentable de la Nación. Agencia de Cooperación Internacional del Japón.

Kay, S., Zhao, B., \& Sui, D. (2015). Can social media clear the air? A case study of the air pollution problem in Chinese cities. Professional geographer, 67(3), 351-363. http://dx.doi.org/10.1080/00330124.2014. 970838

Kleinman, A. (1988). The illness narratives. Suffering, healing and the human condition. New York: Basic books. ISBN: 0465032028, 9780465032020

Krieger, N. (2001). Theories for social epidemiology in the 21st century: an ecosocial perspective. International journal of epidemiology, 30(4), 668-677. https://doi.org/10.1093/ije/30.4.668

Lock, M. (1993). Encounters with Aging. Berkeley: University of California press. ISBN: 0520082214, 9780520082212

Kristeva, J. (1982). Powers of horror: an essay on abjection. New York: Columbia University. ISBN: 0231053479 , 9780231053471

Markowitz, G. \& Rosner, D. (2002). Deceit and denial. The deadly politics 
of industrial pollution. Berkeley, CA: University of California press. ISBN: 9780-520-27582-9

Marquese, R. (2010). O Vale do Paraíba cafeeiro e o regime visual da segunda escravidão: o caso da fazenda Resgate. Anais do museu Paulista: história e cultura material, 18(1), 83-128. http://dx.doi. org/10.1590/S0101-47142010000100004

McClintock, N. (2015). A critical physical geography of urban soil contamination. Geoforum, 65, 69-85. http://dx.doi. org/10.1016/j.geoforum.2015.07.010

Miguez, D. (2002). Inscripta en la piel y en el alma: Cuerpo e identidad en profesionales, Pentecostales y jóvenes delincuentes, Religiâo e sociedade, 22(1), 21-56. Recuperado de http://www. diversidadreligiosa.com.ar/wp-content/ uploads/2013/04/Miguez_Inscripta_Piel_Alma.pdf

Silva, M. (2009). Pobreza y salud en Argentina. Medicina Social, 4(2), 102-112. Recuperado de http://www.socialmedicine. info/index.php/medicinasocial/article/ view/305

Swistun, D. (2013). El derecho a la vivienda digna en un ambiente sano. Desigualdad ambiental, pobreza y salud en la Cuenca Matanza Riachuelo. En L.T.R. Soares (Comp.), Pobreza, desigualdad y salud en América Latina (pp. 287-318). Buenos Aires: CLACSO. ISBN 978-9871891-67-2

U.S.EnvironmentalProtectionAgency.[U.S. EPA] (2005). Integrated Risk Information System (IRIS) on Toluene. National Center for Environmental Assessment, Office of
Research and Development, Washington, DC. Recuperado de https://www.epa.gov/ sites/production/files/2016-09/documents/ toluene.pdf

U.S. Environmental Protection Agency. [U.S. EPA] (2018). Learn about Lead. Recuperado de https://www.epa.gov/lead/ learn-about-lead\#effects

Véron, R. (2006). Remaking urban environments: The political ecology of air pollution in Delhi. Environment and planning $A$, 38(11), 2.093-2.109. http:// dx.doi.org/10.1068/a37449

Villar Navascués, R.A. (2017). La ecología política urbana: veinte años de crítica, autocrítica y ampliación de fronteras en el estudio del metabolismo urbano. Documents d'Anàlisi Geogràfica, 63(1), 173-204. https://doi.org/10.5565/rev/ dag. 325

Yassi, A., Kjellstrom, T., De Kok, T., \& Guidotti, T. (2002). Salud ambiental básica. Ciudad de México: Programa de las Naciones Unidas para el Medio Ambiente Oficina Regional para América Latina y el Caribe. Recuperado de http://www.pnuma. org/educamb/documentos/salud_ambiental_ basica.pdf

Warren, C. (2000). Brush with death. A social history of lead poisoning. Baltimore: John Hopkins University press. ISBN10: 0801868203. ISBN-13: 978-0801868207

Widener, P. (2000). Lead contamination in the 1990s and beyond. A follow-up. En S. Kroll-Smith, P. Brown, \& V. Gunter (Eds.), Illness and the environment. A reader in contested medicine. (pp.260-269). New York: New York University press. 